\title{
A Visible Near-Infrared Chemosensor for Mercury Ion
}

Mei Zhu, Mingjian Yuan, Xiaofeng Liu, Jialiang Xu, Jing Lv, Changshui Huang

Huibiao Liu, Yuliang Li, ${ }^{*}$ Shu Wang, Daoben Zhu

Beijing National Laboratory for Molecular Sciences (BNLMS), CAS Key Laboratory of Organic

Solids, Institute of Chemistry, Chinese Academy of Sciences, Beijing 100080, P.R.China, and

Graduate University of Chinese Academy of Sciences,

Beijing 100080, P.R. China

E-mail : ylli@iccas.ac.cn

\section{Supporting Information}

Table of contents:

§1. Materials.

§2.Measurements.

§3.Methods.

§4.Photophysical Properties of $\mathrm{MCy}-1$ and $\mathrm{MCy}-1 / \mathrm{Hg}^{2+}$.

§5.Binding Analysis for $\mathrm{MCy}-1 / \mathrm{Hg}^{2+}$.

§6 Synthesis.

\$7 The characterization data of all compounds. 


\section{§1. Materials.}

Unless otherwise stated, reagents and solvents were commercially obtained and use without further purification.

\section{§2. Measurements.}

The absorption spectra were measured on a Hitachi U-3010 spectrometer. Fluorescence spectra were measured on a Hitachi F-4500 fluorometer. ${ }^{1} \mathrm{H}$ NMR and ${ }^{13} \mathrm{C}$ NMR spectra were obtained on a Bruker Avance DPS-400 spectrometer, respectively. MALDI-TOF mass spectrometric measurements were performed on Bruker Biflex III MALDI-TOF (both positive and negative ion reflector mode)

\section{§3. Methods.}

\subsection{Determination of the binding constant}

The binding constant $\mathrm{K}$ of $\mathrm{MCy}-1 / \mathrm{Hg}^{2+}$ complex were determined from the following Benesi-Hildebrand equation $^{12}$ :

$$
\frac{1}{A-A_{0}}=\frac{a}{a-b} \cdot\left[\frac{1}{K[M]}+1\right]
$$

Where $\mathrm{K}=$ Binding constant;

$\mathrm{A}_{0}=$ The observed absorption in the absence of cation;

$\mathrm{A}=$ The observed absorption the cation-added;

$[\mathrm{M}]=$ The concentration of the cation-added;

$\mathrm{a}$ and $\mathrm{b}$ are constants, the binding constant value $\mathrm{K}$ was evaluated graphically by plotting $1 / \Delta \mathrm{A}$ against $1 /[\mathrm{M}]$ 


\subsection{Determination of the detection limit}

The detection limit DL of MCy-1 for $\mathrm{Hg}^{2+}$ was determined from the following equation:

$\mathrm{DL}=\mathrm{K}^{*} \mathrm{Sb} 1 / \mathrm{S}$

Where $\mathrm{K}=2$ or 3 ; $\mathrm{Sb} 1$ is the standard deviation of the blank solution; $\mathrm{S}$ is the slope of the calibration curve.

\section{§4.Photophysical Properties of MCy-1 and $\mathrm{MCy}-1 / \mathrm{Hg}^{2+}$.}

\subsection{Photophysical Properties of MCy-1 and $\mathrm{MCy}-1 / \mathrm{Hg}^{2+}$}

\begin{tabular}{c|cccc}
\hline compounds & $\lambda_{\mathrm{ab}(\mathrm{nm})}$ & $\lambda_{\mathrm{em}(\mathrm{nm})}$ & $\varepsilon^{\mathrm{a}}$ & $\Phi_{f}^{b}$ \\
\hline MCy-1 & 695 & 777 & 86000 & 0.101 \\
\hline $\mathrm{MCy}-1 / \mathrm{Hg}^{2+}$ & 817 & 777 & 190000 & 0.028 \\
\hline
\end{tabular}

(a) Molar extinction coefficients are in $\mathrm{M}^{-1} \cdot \mathrm{cm}^{-1}$ and in the maximum of the highest peak. (b) The fluorescence quantum yields of MCy-1 was determined in methanol in reference to cresyl violet perchlorate $\left(\Phi_{f}=0.54\right.$ in methanol $),{ }^{3}$ while $\mathrm{MCy}-1 / \mathrm{Hg}^{2+}$ in methanol was in reference to compound $1\left(\Phi_{f}=0.17\right.$ in methanol $){ }^{1}$

\subsection{Excitation spectra of MCy-1}

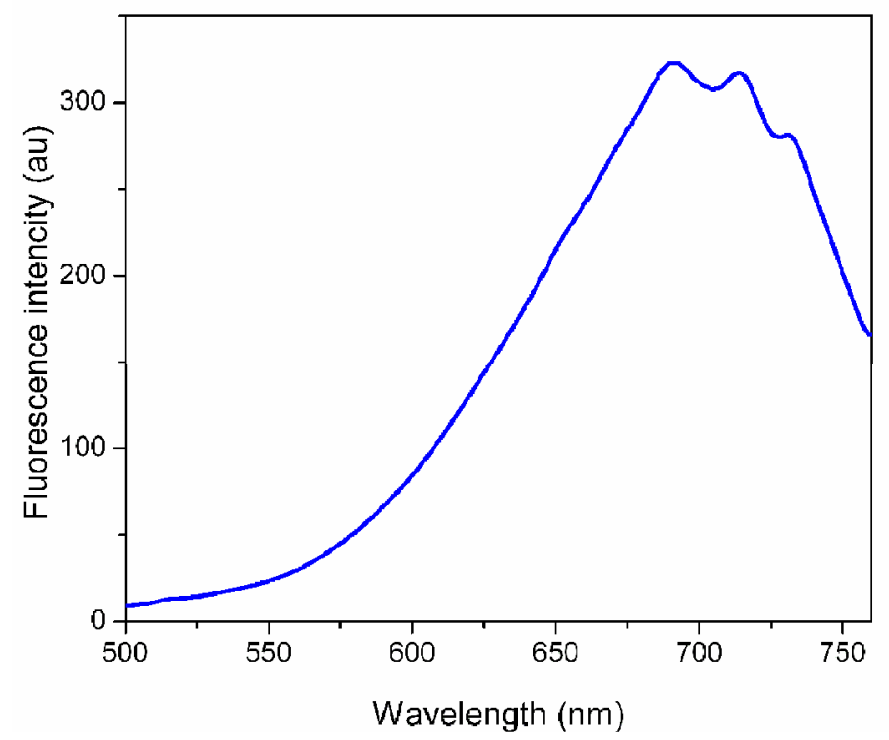

Figure S4 Excitation spectra of MCy-1 in methanol 


\section{§5.Binding Analysis for $\mathrm{MCy}-\mathbf{1} / \mathrm{Hg}^{2+}$}

\subsection{Benesi-Hildebrand plots}

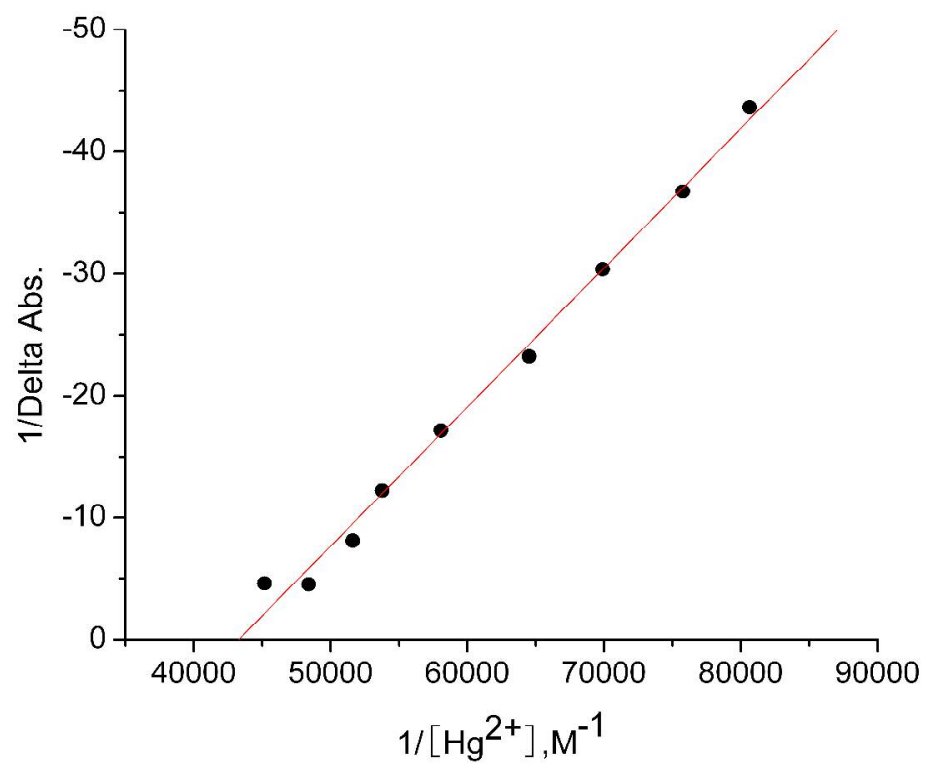

Figure S2. Benesi-Hildebrand analysis of $\mathrm{MCy}-1$ at different $\mathrm{Hg}^{2+}$ concentrations.

$\mathrm{Y}=\mathrm{A}+\mathrm{B} * \mathrm{X}$

Parameter

A

B
Value

49.41694

$-0.00114$
Error

2.27825

$3.67455 \mathrm{E}^{-5}$

\begin{tabular}{|c|c|c|c|}
\hline $\mathrm{R}$ & SD & $\mathrm{N}$ & $\mathrm{P}$ \\
\hline-0.99639 & 1.30126 & 9 & $<0.0001$ \\
\hline \multicolumn{4}{|c|}{$\mathrm{Ks}=\mathrm{A} / \mathrm{B}=(49.41694 / 11.4) \times 10^{4}=4.335 \times 10^{4}$} \\
\hline \multicolumn{4}{|c|}{$\Delta \mathrm{Ks}=|\Delta \mathrm{A} / \mathrm{A}-\Delta \mathrm{B} / \mathrm{B}| \times \mathrm{Ks}=0.014 \times 10^{4}$} \\
\hline
\end{tabular}


$5.2{ }^{1} \mathrm{H}$ NMR spectra of MCy-1 before and after addition of mercury ions

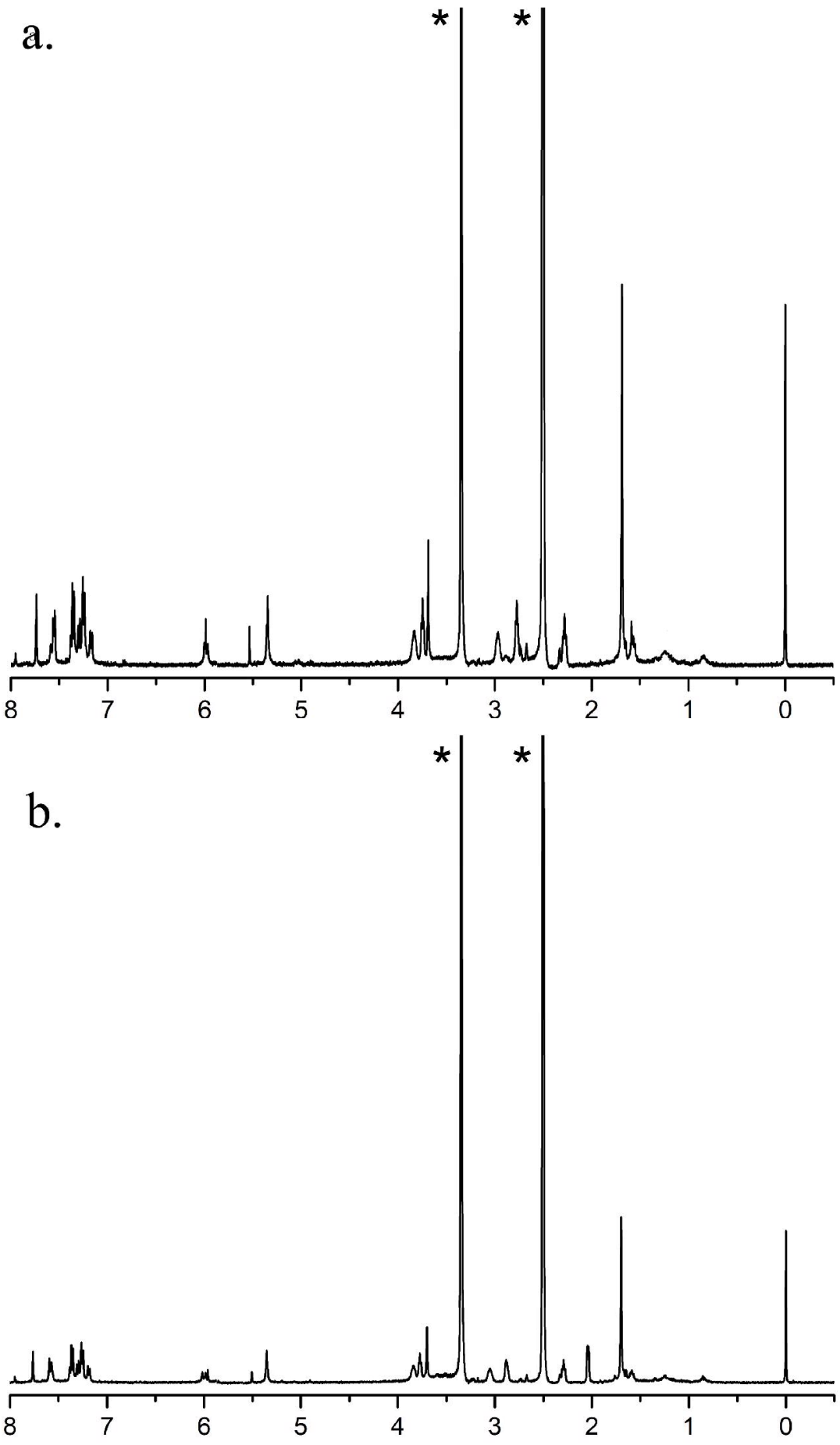

Figure S3 ${ }^{1} \mathrm{HNMR}$ spectra (400 MHz, DMSO- $d_{6}$ ) of MCy-1 before (a) and after (b) addition of 10 equiv mercury ions. 


\section{§6. Synthesis}

Compound 1 and 2 ( dithia-dioxa-monoaza crown ether) were synthesized according to the literature. ${ }^{1,2}$

\section{Synthesis and characterization data of MCy-1}

Preparation of MCy-1. $79.5 \mathrm{mg}(0.1 \mathrm{mmol})$ of cyanine and $125 \mathrm{mg}(0.5 \mathrm{mmol})$ of dithia-dioxa-monoaza crown ether were dissolved in $10 \mathrm{ml}$ anhydrous DMF in a $25 \mathrm{~mL}$ round bottom flask. The mixture was stirred at $90{ }^{\circ} \mathrm{C}$ under argon for 3 hours. Then it was cooled to room temperature and added to $120 \mathrm{~mL}$ of ether with violent stirring. The obtained blue solid was filtered and dried under vacuum, then purified on column chromatography on silica gel using methanol-DCM mixture as eluent to give an dark blue product. $(53.5 \mathrm{mg}, 53 \%) . \quad{ }^{1} \mathrm{H}$ NMR $\left(400 \mathrm{MHz}, \mathrm{DMSO}-d_{6}\right)$ : $\delta 1.23\left(\mathrm{~m}, 2 \mathrm{H}, \mathrm{CH}_{2}\right), 1.68(\mathrm{~s}, 12 \mathrm{H}), 2.28-2.76(\mathrm{t}, 4 \mathrm{H}, J=4.88 \mathrm{~Hz}), 2.96(\mathrm{t}, 4 \mathrm{H}), 3.74(\mathrm{t}, 4 \mathrm{H}, J=4.88$ Hz), $3.83(\mathrm{~s}, 4 \mathrm{H}), 5.34(\mathrm{~s}, 4 \mathrm{H}), 5.97-6.00(\mathrm{~d}, 2 \mathrm{H} \mathrm{J}=13.4 \mathrm{~Hz}, \mathrm{CH}), 7.15-7.17(\mathrm{~d}, 2 \mathrm{H}, \mathrm{CH}), 7.23-7.25(\mathrm{~d}$, $4 \mathrm{H}, \mathrm{CH}), 7.28-7.30(\mathrm{~d}, 2 \mathrm{H}, \mathrm{CH}), 7.34-7.38(\mathrm{~m}, 4 \mathrm{H}, \mathrm{CH}), 7.55-7.58(\mathrm{~m}, 4 \mathrm{H}, \mathrm{CH}), 7.74(\mathrm{~s}, 2 \mathrm{H}, \mathrm{CH}) .{ }^{13} \mathrm{C}$ NMR (150 MHz, DMSO- $\left.d_{6}\right): \delta 21.8,24.5,29.1,29.2,29.6,31.3,32.2,32.5,36.3,40.6,46.9,48.3$, $56.2,70.9,73.5,98.1,109.6,120.4,125.3,126.6,127.1,128.1,129.5,136.0,140.1,142.3,143.5$, 143.6, 144.8, 162.9, 169.9, 173.5. Q-TOFMS: $[\mathrm{M}+\mathrm{H}]^{+}$calculated: 1010.35, measured: 1010.6. 


\section{\$7 The characterization data of all compounds.}

${ }^{1} \mathrm{H}$ NMR spectra of compound 1

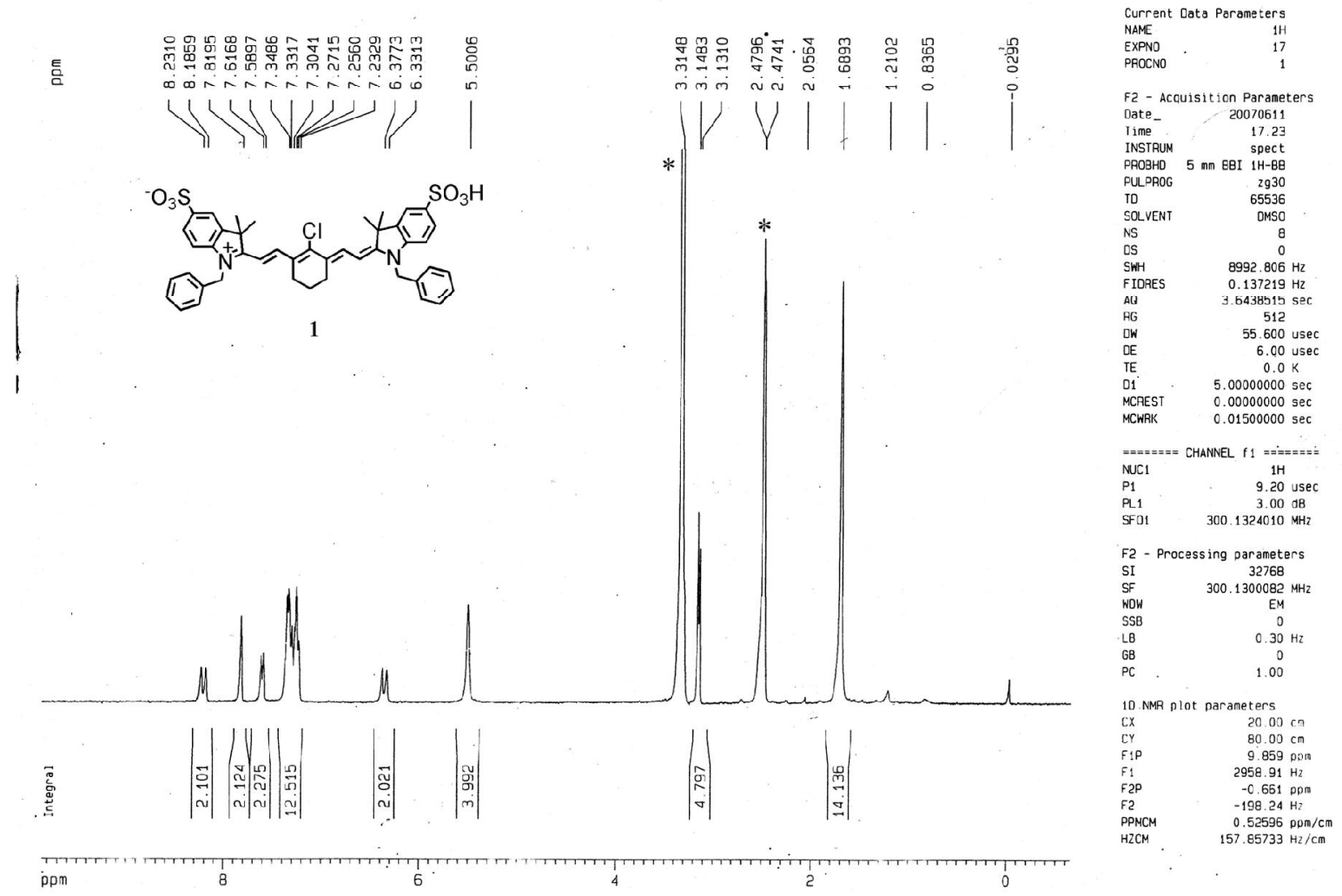

${ }^{13} \mathrm{C}$ NMR spectra of compound 1

\section{?}
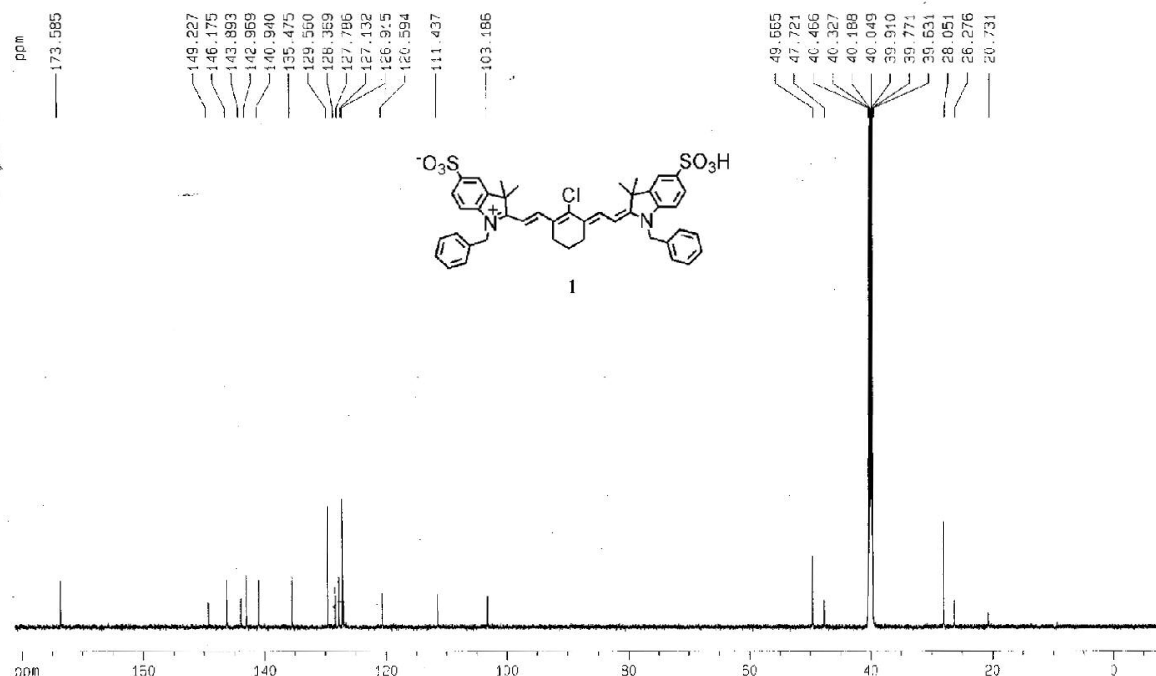

I

150

$\frac{1}{120}$

30

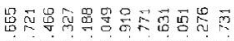

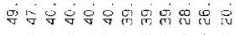

(2) 1211

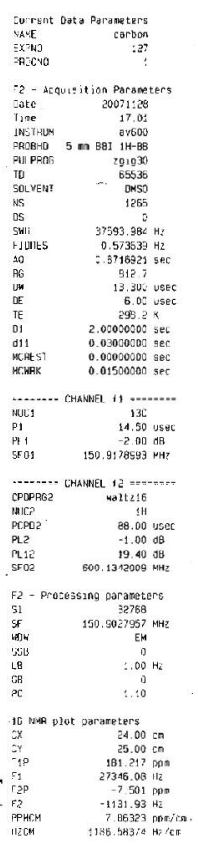


ESI-MS spectrum of compound 1

\#:1 Ret.Time:Averaged 0.107-0.827(Scan\#:5-32)

Mass Peaks:249 Base Peak:794.10(247908) Polarity:Neg Segmentl - Eventl

Intensity

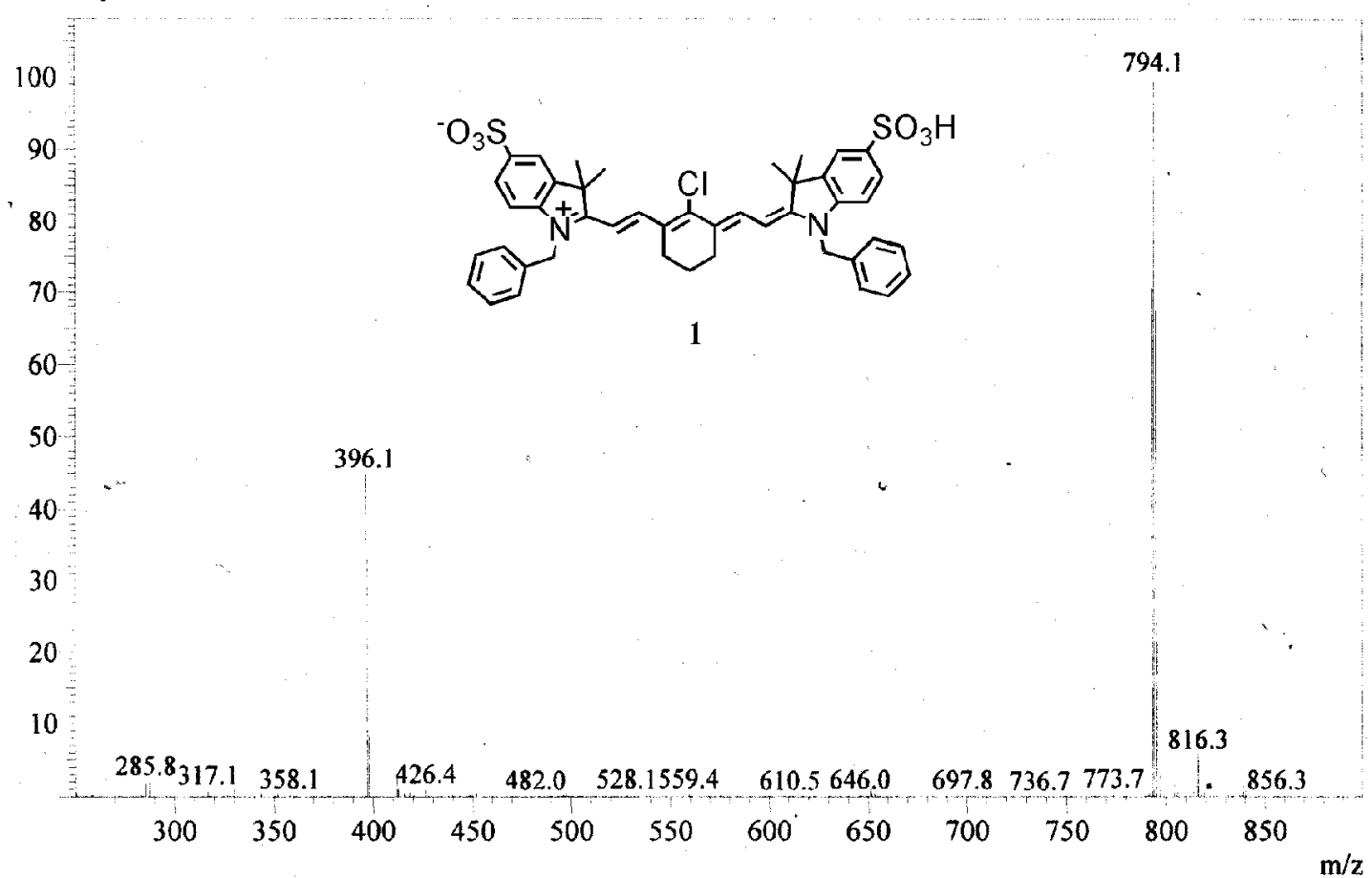

${ }^{1} \mathrm{H}$ NMR spectra of compound 2

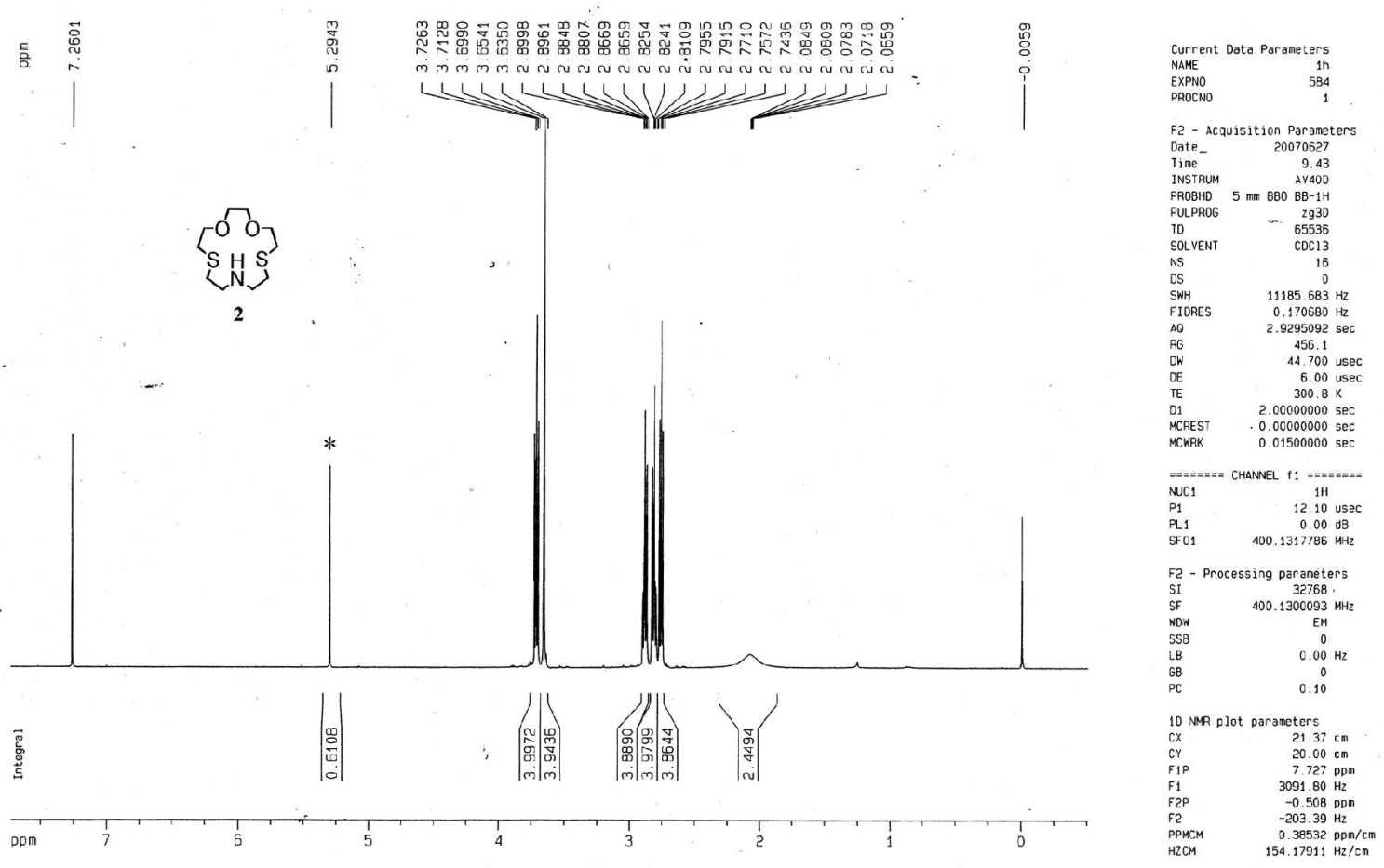


${ }^{13} \mathrm{C}$ NMR spectra of compound 2

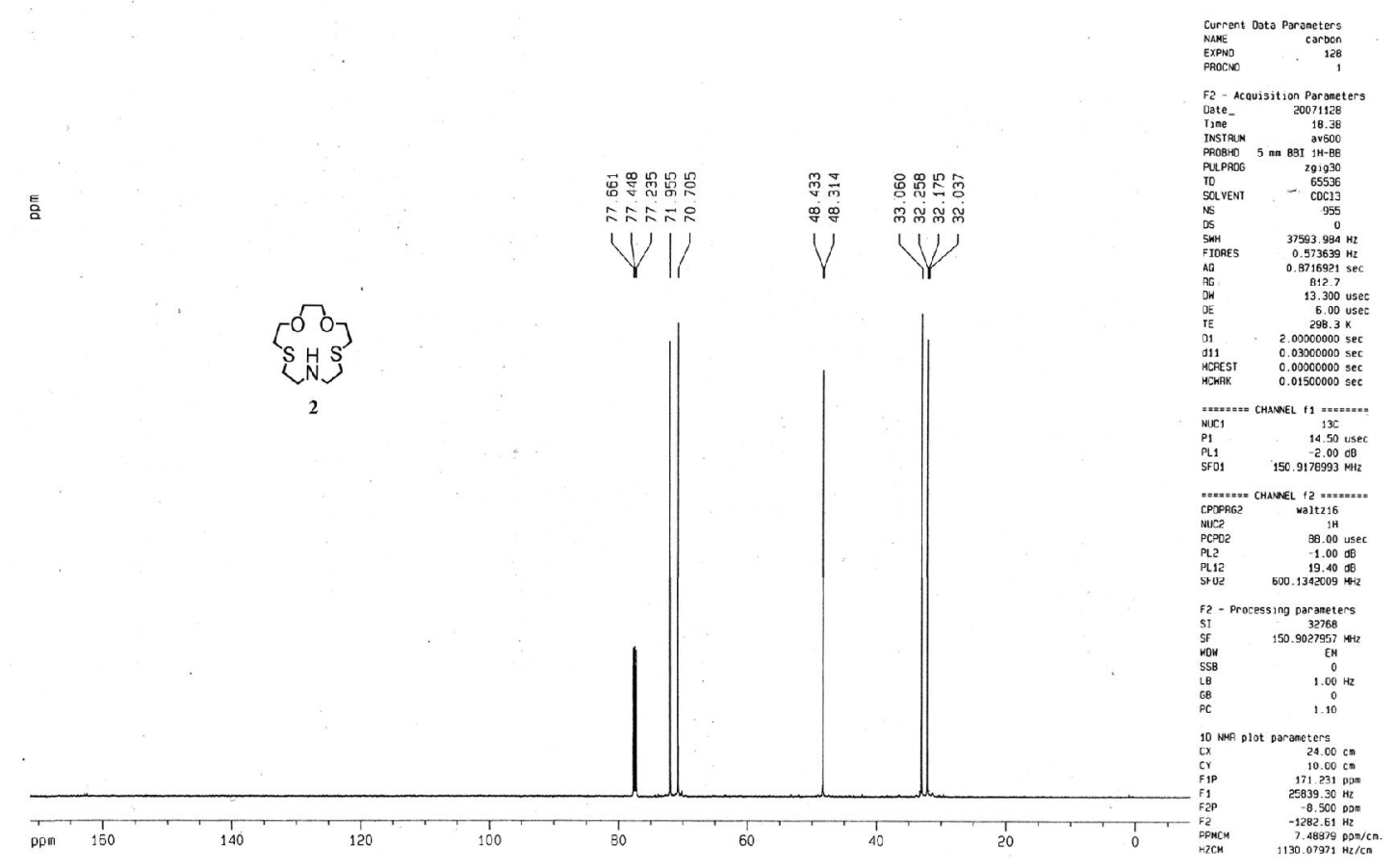

ESI-MS spectrum of compound 2

ESI-MS Spectrum,zm2

\#:1 Ret.Time:Averaged 2.613-3.200(Scan\#:99-121)

Mass Peaks:68 Base Peak:252.15(10447249) Polarity:Pos Segmentl - Event 1 Intensity

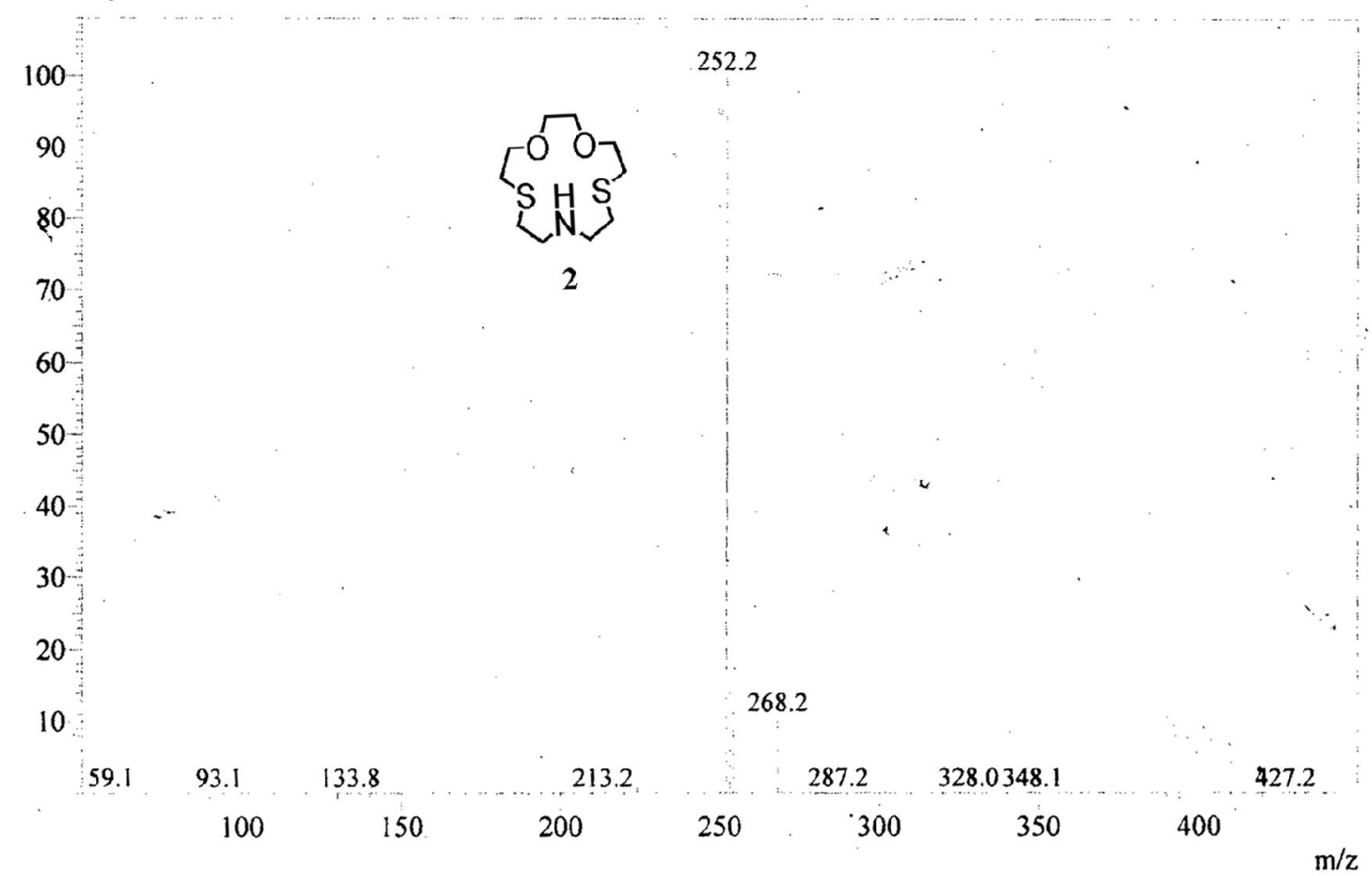




\section{${ }^{1} \mathrm{H}$ NMR spectra of MCy-1}

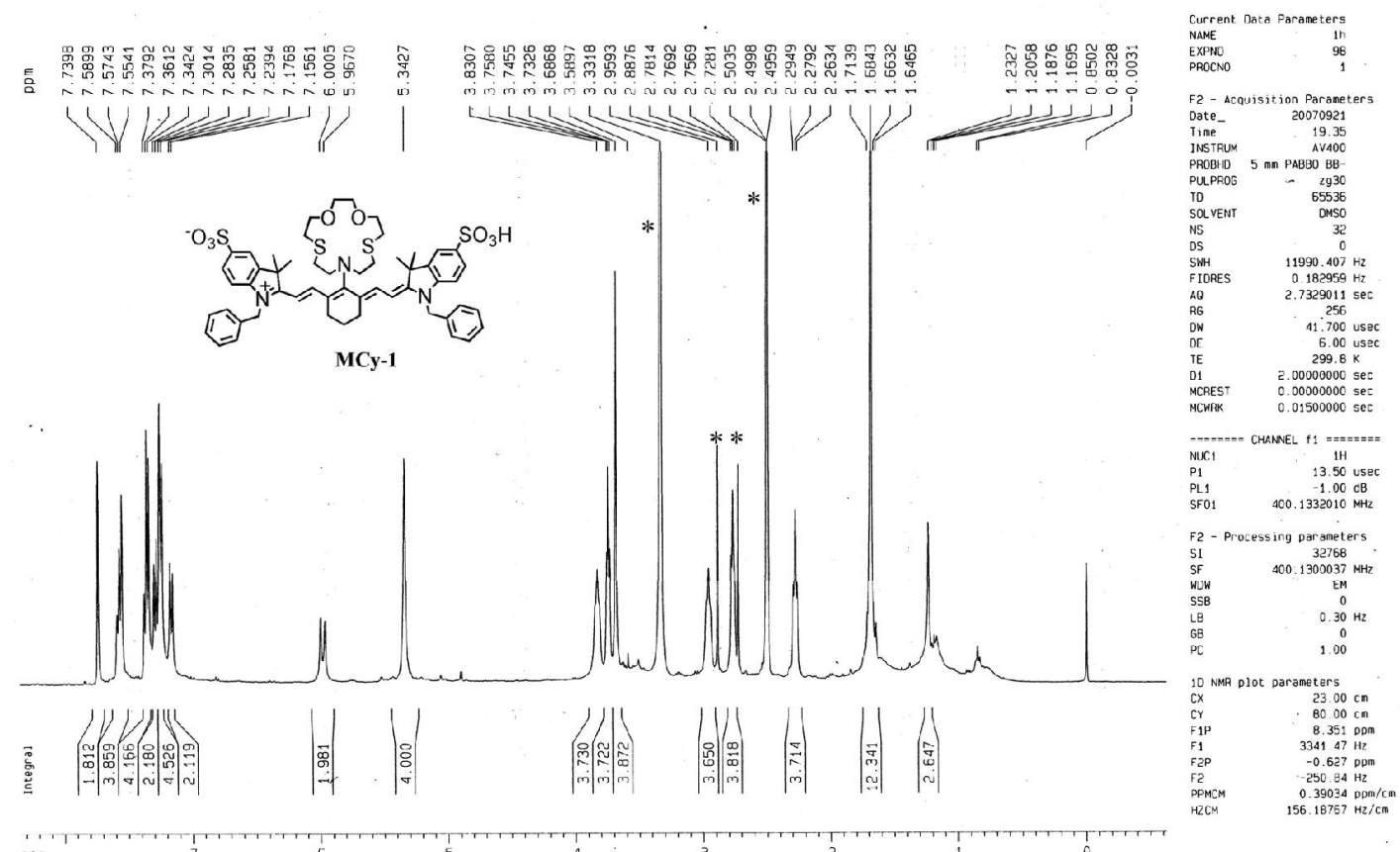

${ }^{13} \mathrm{C}$ NMR spectra of MCy-1
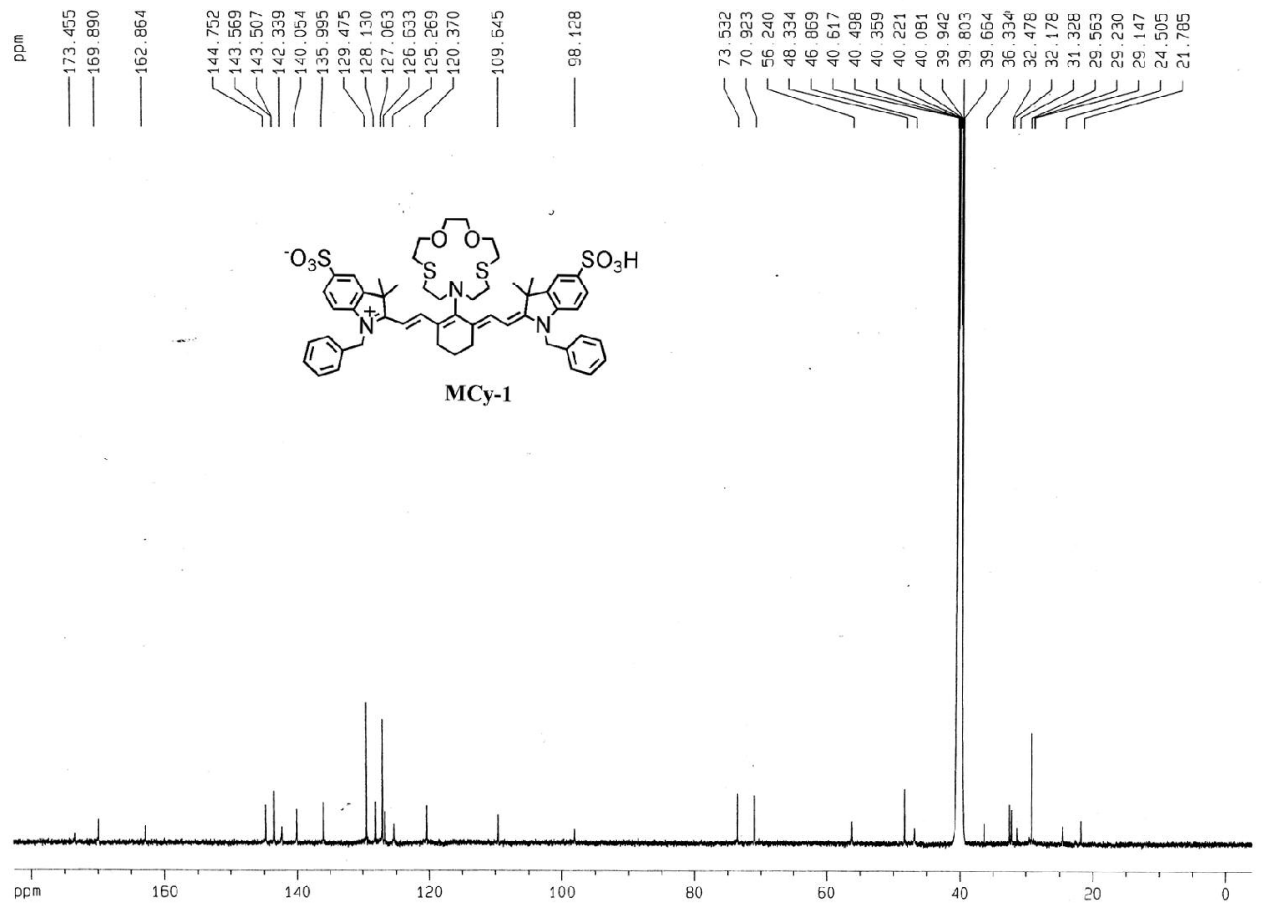

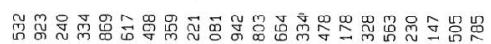

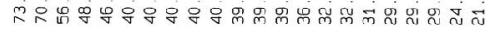

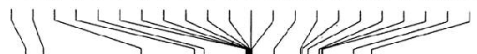

)

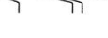




\section{MALDI-TOF of MCy-1}

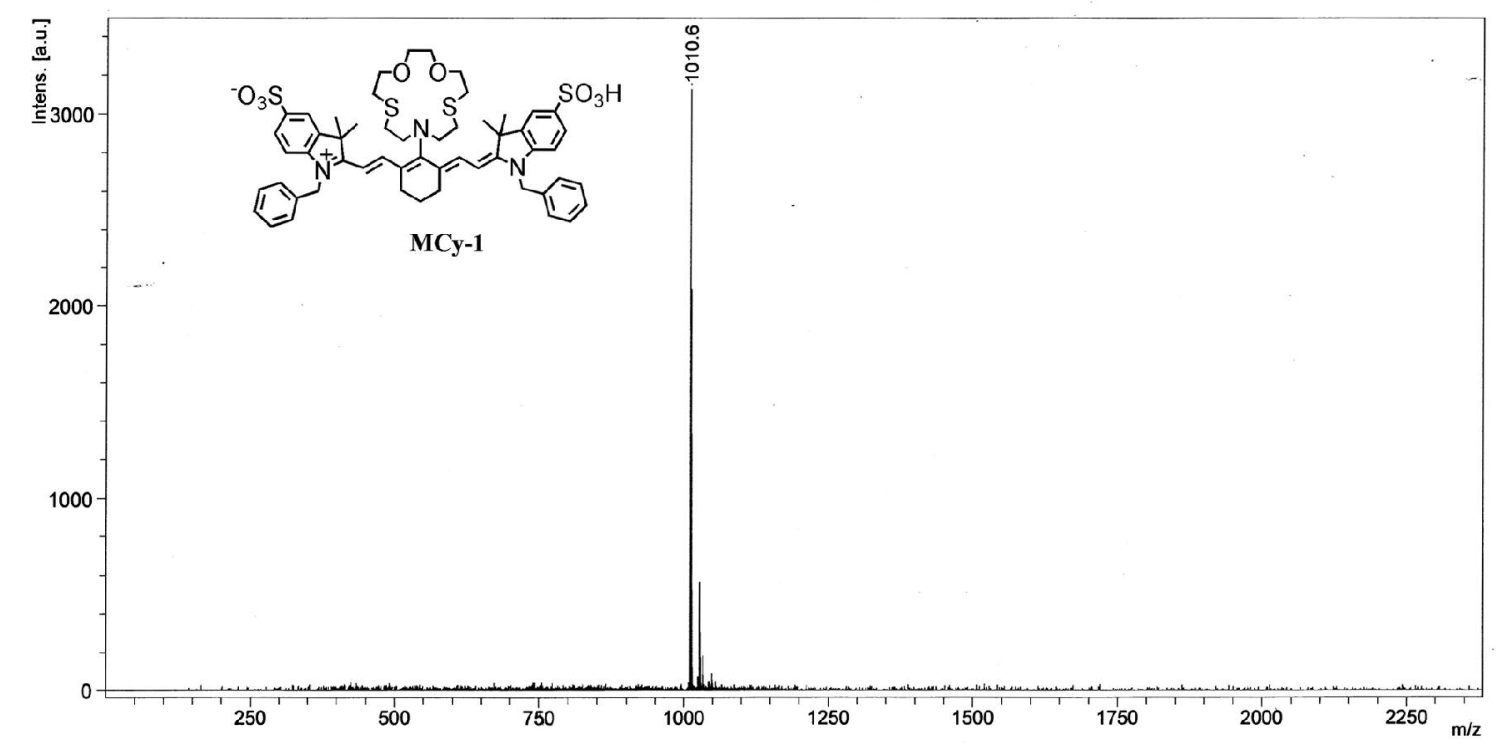

ESI-MS of MCy-1/ $\mathrm{Hg}^{2+}$ 


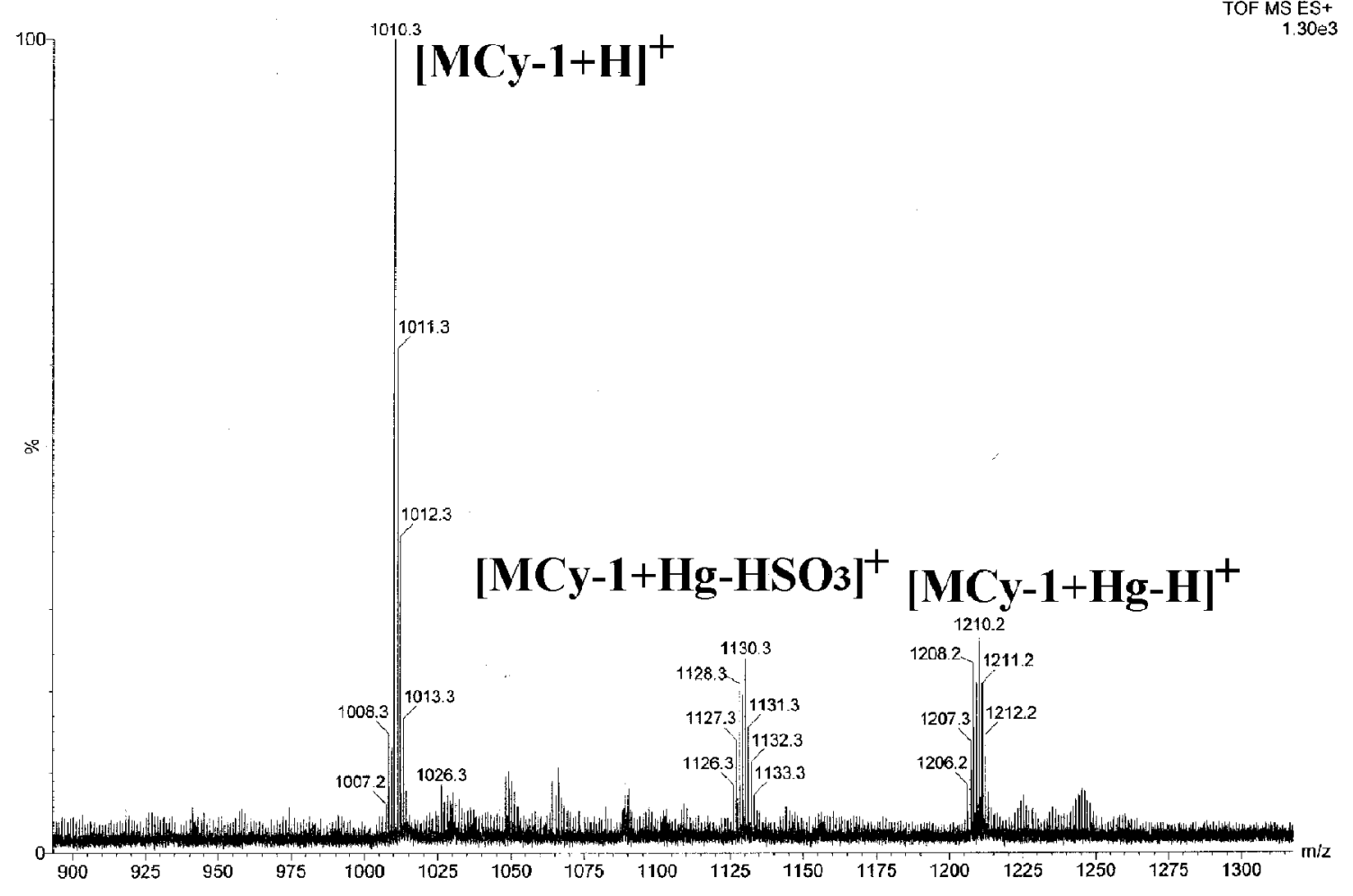

References

(1) Peng, X.; Song, F.; Lu, E.; Wang, Y.; Zhou, W.; Fan, J.; Gao, Y. J. Am. Chem. Soc. 2005, 127, 4170-4171.

(2) van de Water, L. A.; Buijs, W.; Driessen, W. L.; Reedijk, J. New J. Chem., 2001, 25, 243-249.

(3) Douglas Magde, James H. Brannon, Teresa L. Cremers, John Olmsted, III, J. Phys. Chem. 1979, 83, 696-699. 